\title{
Research of Type 2 Diabetes Patients' Problem Areas and Affecting Factors
}

\author{
Sebahat Atalikoğlu Başkan1*, Mehtap Tan² \\ ${ }^{1}$ Faculty of Health Sciences, Erzincan University, Erzincan, Turkey \\ ${ }^{2}$ Faculty of Health Sciences, Atatürk University, Erzurum, Turkey \\ Email: *atalikoglu_sebahat@hotmail.com,mtan@atauni.edu.tr
}

How to cite this paper: Başkan, S.A. and Tan, M. (2017) Research of Type 2 Diabetes Patients' Problem Areas and Affecting Factors. Journal of Diabetes Mellitus, 7, 175-183. https://doi.org/10.4236/jdm.2017.73014

Received: July 28, 2017

Accepted: August 14, 2017

Published: August 17, 2017

Copyright $\odot 2017$ by authors and Scientific Research Publishing Inc. This work is licensed under the Creative Commons Attribution International License (CC BY 4.0).

http://creativecommons.org/licenses/by/4.0/

\begin{abstract}
Background: The study was descriptively conducted in order to determine problem areas and the affecting factors among the Type II diabetes patients. Methods: The study was carried out between August and October, 2011 in the Endocrinology Polyclinic in Adiyaman, Turkey. The population of the study was made up by Type II diabetes patients who were diagnosed with diabetes at least one year ago and came to Endocrinology Polyclinics at the study period. The sample of the research consisted of 188 patients who were recruited using random sampling method, were diagnosed as diabetes for at least one year. Data were collected through a Personal Information Form and Problem Areas in Diabetes (PAID) Scale. The data obtained were assessed in SPSS packet programme by using arithmetic average, percentage, variance analysis and t-test. Results: It was found out that the participant patients had serious problems in diabetes and their mean PAID score was $68.17 \pm 16.16$. The difference between patients BMI values and mean PAID scores was statistically significant $(\mathrm{p}<0.05)$. Conclusion: It was established that the patients included in the study experienced a serious diabetes problem. In addition to the results, this study could be used to help develop nursing interventions.
\end{abstract}

\section{Keywords}

Problem Areas, Type II Diabetes, Nursing, Turkey

\section{Introduction}

Diabetes is a chronic illness that is considered as one of the most challenging health problems in the 21st century [1] [2] [3] [4]. Diabetes results in chronic complications including microvascular and macrovascular disorders. Evidence has also shown that cardiovascular disease is the major cause of morbidity and mortality for patients with diabetes and has significant contribution to the direct and indirect costs of diabetes [5]. Diabetes and its complications affect the 
society's economic status and have a great impact on individuals, families, healthcare systems and countries, not only due to cost of treatment, but also social costs and loss of working days [6] [7].

Demographic characteristics were obtained using a self-report survey. Body mass index (BMI) was calculated from self-reported height and weight entries. The most recent hemoglobin Alc (HbAlc) readings within the last year were collected via chart extractions after all surveys were complete.

Incidence of diabetes mellitus has been increasing fast and its prevalence show a similar tendency [1]. According to WHO's data, Type II diabetes has been increasing especially in the developing countries and the disease and its complications have become a serious health problem [3]. According to the data of International Diabetes Federation, it is known that there are 356 million diabetic people in 2011 in world and it is estimated that this number will rise to 552 million people by 2030. It is reported that there are 6 million diabetic patients in Turkey [1] [2] [3] [4]. Type II diabetes is a metabolic disease characterized with obesity and insulin resistance due to unused insulin in tissue and insulin secretion disorder, symptoms of which are slight or not evident and chronic complications of which are commonly seen. It is seen that $20 \%$ of the newly diagnosed Type II diabetes have retinopathy, $8 \%$ had nephropathy and $9 \%$ had neuropathy [7] [8].

When diabetes mellitus is not cured well, its risk for complications is higher and its cost increases. Treatment requires not only certain medicines but also a change in life style, which causes psychological, emotional, social and psycho-social problems because the individual has to change his/her habitual behaviors [9].

Due to many concomitant problems in diabetes, a broader approach is needed not only for glycemic control but also for all problems in the treatment of the patient. Therefore, it is important to explore individual problem areas of patients, too [10]. Exploration of problem areas among the diabetic patients and of the affecting factors will help increase the quality of life and will provide a nursing care of quality targeting at the problems [11].

Care of diabetes is a dynamic process that differs from person to person and requires using different individual approaches for each person and making new planning. Holistic and patient-centered approaches to be used for the treatment of the diabetic patients make patients join his/her treatment and take responsibility for the treatment [12]. It is inevitable to get the help of a specialist in order to continue the care and the treatment of diabetes. Holistic care process deals with patients physically, psychologically and socio-culturally and provides disease management with training, counseling and treatment. The aim is to give the care that the diabetic individual needs in all aspects [13].

\section{Methods}

\subsection{Study Design}

The study was descriptively conducted in order to determine problem areas and 
the affecting factors among the Type II diabetes patients.

\subsection{Subject Population and Sample Size}

The research was conducted at the Endocrinology Policlinics of Adiyaman State Hospital between August and October, 2011. The population of the study was made up by Type II diabetes patients who were diagnosed with diabetes at least one year ago and came to Endocrinology Policlinics at the study period. The sample of the research was consisted of 188 patients who were recruited using random sampling method, were diagnosed as diabetes for at least one year, had no auditory, understanding and speaking problems and accepted to participate in the study.

\subsection{Data Collecting Forms Used in the Study}

The data of the study were gathered using Personal Information Form and Problem Areas in Diabetes (PAID) Scale. The data were gathered by the researcher at the endocrinology policlinics on Mondays, Tuesdays, Wednesdays and Thursdays using face to face interview method. The data could not be collected on Fridays because patient admission was not possible on Fridays at the Endocrinology Policlinics of Adiyaman State Hospital.

Personal Information Form: Participants were asked to fill in a form that included descriptive characteristics (age, gender, marital status, educational status, profession, family type, disease duration, BMI and diabetes history in the family of the patients).

Problem Areas in Diabetes (PAID) Scale: The scale was developed by Polonsky et al. (1995) in order to measure problem areas of diabetes patients [14]. It is a Likert-type scale and is consisted of 20 statements about emotional distress in diabetes. The participants are asked to mark one of the options $(0=$ not a problem, 1 = a slight problem, 2 = a moderate problem, $3=$ somewhat serious problem, $4=$ a serious problem). Point given each statement is taken into consideration and raw score is multiplied by 1.25 and real score is obtained. Thus, the lowest score is 0 whereas the highest score is 100 . Higher scores obtained from the scale indicate that problems patients experience are more severe. Reliability and validity tests of PAID were performed by Polonsky et al. (1995) and Cronbach's a reliability coefficient was established as 0.90 . Reliability and validity tests of PAID were performed by Elkoca (2010) in Turkiye and Cronbach's $\alpha$ reliability coefficient was established as 0.88 [11]. In the study, Cronbach's a reliability coefficient was found to be as 0.82 as an indication of homogeneity and internal consistency of PAID.

\subsection{Data Assessment}

The data were analyzed using SPSS (Statistical Package for Social Science) 17 and means, standard deviation, Cronbach's $\alpha$, t-test, ANOVA variance analysis.

\subsection{Ethical Concerns of the Study}

The study was approved by the Ethical Committee of the Health Science Institute 
of the university, written official permissions were gained from the Adiyaman State Hospital and informed consent was obtained from each participant. The patients were informed of the aim of the study and were assured that they had the right to refuse to participate or to leave the study whenever they wished.

\section{Results}

When mean PAID scores of the patients were examined, it was seen that mean score was $68.17 \pm 16.16$ and general idea about problem areas was regarded as "serious problem" according to these mean PAID score (Table 1).

Table 2 demonstrated comparison of the mean scores that the patients obtained from PAID in terms of their descriptive characteristics. As the result of the study, when mean PAID scores of the patients were analyzed in relation with gender it was found out that mean PAID scores of the male patients were 69.24 \pm 15.12 whereas mean PAID scores of the female patients were $67.62 \pm 16.71$ and no statistically significant difference existed between male patients and female patients ( $p>0.05$ ). Mean PAID scores of the patients aged between 56 and 65 were higher $(71.64 \pm 15.11)$ as compared with patients of other age groups. However, no statistically significant difference existed between mean PAID scores in terms of age $(p>0.05)$. Mean age of the participant patients was 56.71 \pm 10.06 .

When mean PAID scores of the patients were examined in terms of marital status, it was seen that mean PAID scores of the single patients (71.81 \pm 12.36$)$ were higher than those married patients but no statistically significant difference existed between mean PAID scores in terms of marital status ( $p>0.05)$.

When mean PAID scores of the patients were examined in terms of educational status, it was noted that mean PAID scores of the patients who had primary school degree $(70.18 \pm 16.89)$ were higher than those who had high school degree and higher school degree and who were illiterate but no statistically significant difference existed between mean PAID scores in terms of educational status ( $\mathrm{p}>0.05)$.

Mean PAID scores of those who were self-employed (69.72 \pm 17.64$)$ were higher compared to patients of other professions. Yet, no statistically significant difference existed between mean PAID scores in terms of professions ( $p$ > $0.05)$.

When patients were examined in terms of mean PAID scores in relation with family type, mean PAID scores of those who had extended family $(71.16 \pm 13.44)$ were higher compared to patients who had nuclear family but there was no statistically significant difference in terms of family type $(p>0.05)$.

Mean PAID scores of the patients who were diabetic patient for $\geq 10$ years

Table 1. Mean Problem Areas in Diabetes (PAID) Scale scores of the patients.

\begin{tabular}{ccccc}
\hline & $\mathbf{n}$ & Minimum-Maximum & Minimum-Maximum & $\mathrm{X} \pm \mathrm{SD}$ \\
\hline PAID & 188 & $0-100$ & $16.2-92.5$ & $68.17 \pm 16.16$ \\
\hline
\end{tabular}


Table 2. Comparison of PAID scores of the patients in terms of descriptive characteristics $(\mathrm{n}=188)$.

\begin{tabular}{|c|c|c|c|}
\hline Characteristics & $\mathbf{n}$ & $\mathrm{X} \pm \mathrm{SD}$ & P-values \\
\hline \multicolumn{4}{|l|}{ Gender } \\
\hline Female & 124 & $67.62 \pm 16.71$ & \\
\hline Male & 64 & $69.24 \pm 15.12$ & \\
\hline \multicolumn{4}{|l|}{ Age } \\
\hline$\leq 45$ years & 24 & $64.90 \pm 19.54$ & \multirow{5}{*}{ p: 0.138} \\
\hline $46-55$ years & 64 & $67.29 \pm 15.28$ & \\
\hline $56-65$ years & 68 & $71.64 \pm 15.11$ & \\
\hline$\geq 66$ years & 32 & $65.04 \pm 16.69$ & \\
\hline Age $(X \pm S D)$ & & $56.71 \pm 10.06$ & \\
\hline \multicolumn{4}{|l|}{ Marital Status } \\
\hline Married & 159 & $67.50 \pm 16.71$ & \multirow{2}{*}{ p: 0.188} \\
\hline Single & 29 & $71.81 \pm 12.36$ & \\
\hline \multicolumn{4}{|l|}{ Educational Status } \\
\hline Primary School & 75 & $70.18 \pm 16.89$ & \multirow{4}{*}{ p: 0.299} \\
\hline High School & 22 & $69.66 \pm 13.48$ & \\
\hline Higher School & 12 & $61.98 \pm 17.66$ & \\
\hline Illiterate & 79 & $66.79 \pm 15.83$ & \\
\hline \multicolumn{4}{|l|}{ Employment } \\
\hline State officer & 9 & $64.30 \pm 12.82$ & \multirow{4}{*}{ p: 0.681} \\
\hline Self-employed & 32 & $69.72 \pm 17.64$ & \\
\hline Retired & 34 & $66.02 \pm 15.64$ & \\
\hline Housewife & 113 & $68.68 \pm 16.20$ & \\
\hline \multicolumn{4}{|l|}{ Family Type } \\
\hline Nuclear Family & 159 & $67.62 \pm 16.59$ & \multirow{2}{*}{ p: 0.270} \\
\hline Extended Family & 29 & $71.16 \pm 13.44$ & \\
\hline \multicolumn{4}{|l|}{ Disease Duration } \\
\hline $1-3$ years & 37 & $64.36 \pm 18.56$ & \multirow{4}{*}{ p: 0.106} \\
\hline $4-6$ years & 44 & $66.68 \pm 17.98$ & \\
\hline $7-9$ years & 21 & $65.48 \pm 14.86$ & \\
\hline$\geq 10$ years & 86 & $71.24 \pm 13.95$ & \\
\hline \multicolumn{4}{|c|}{ Family Diabetes History } \\
\hline No & 81 & $68.23 \pm 15.73$ & \multirow{2}{*}{ p: 0.968} \\
\hline $\mathrm{Yes}^{\dagger}$ & 107 & $68.13 \pm 16.56$ & \\
\hline \multicolumn{4}{|l|}{ BMI } \\
\hline Under weight & 2 & $59.38 \pm 18.56$ & \multirow{4}{*}{ p: 0.044} \\
\hline Normal & 33 & $67.31 \pm 18.50$ & \\
\hline Slightly overweight & 103 & $70.93 \pm 14.40$ & \\
\hline Overweight & 50 & $63.40 \pm 17.08$ & \\
\hline
\end{tabular}

${ }^{\dagger}$ Among the first degree family members.

(71.24 \pm 13.95$)$ were higher than the patients who had diabetes for different time periods. It was found out that there was no statistically significant difference among the groups in terms of mean PAID scores in relation with disease duration $(\mathrm{p}>0.05)$.

When mean PAID scores were analyzed in terms of family diabetes history, those who had no family diabetes history had higher PAID scores $(68.23 \pm$ 15.73) than the scores of those whose first degree relatives had diabetes (68.13 \pm 
16.56) but no statistically significant difference was found in terms of mean PAID scores in relation with family diabetes history $(\mathrm{p}>0.05)$.

PAID scores of those who were slightly overweight according to BMI (70.93 \pm 14.40) were found to be higher than the patients who were of under-weight, normal weight and overweight and there was a significant difference in terms of PAID scores in relation with BMI values of patients $(\mathrm{p}<0.05)$.

\section{Discussion}

Mean PAID score of the patients was $68.17 \pm 16.16$ in the study. General idea about problem areas was regarded as "serious problem". In a study conducted by Delehanty et al. [15), it was found out that general idea about problem areas was regarded as "serious problem". The study of Nozaki et al. [16] reported that mean PAID score was 33.0 and general idea about problem areas was regarded as "moderate problem". The study of Eom et al. [17] pointed out that mean PAID score was $47.5 \pm 17.5$ and patients perceived diabetes as "slight problem". In the study of Fonda et al. [18], it was seen that mean PAID score was 25.1 and general idea about diabetes was regarded as "somewhat serious problem". In the studies made about diabetes, mean PAID scores were lower than the score obtained in this study. We were of the opinion that this difference may have been associated with the status whether or not the participants used coping methods of the problem effectively.

As the result of the study, although it was found out that mean PAID scores of the male patients were higher than female patients, the difference was insignificant. In a study by Welch et al. [19], it was noted that no significant relation existed between in terms of their mean PAID scores in relation with gender of the patients. Our study results concurred with the results of study of Welch et al. but, the results of the study of Snoek [20] and Elkoca [11] demonstrated that mean PAID scores of women were higher than men and the difference was statistically significant. The study of Ghanbari et al. [21] indicated that men were less affected by diabetes diseases than women. This result of the study made us think that male patients perceived diabetes as a less serious problem. In the study of Huis In 'T Veld et al. [22], it was found out that mean PAID scores of women were considerably higher than men and the difference was statistically important. We were of the opinion that the reason of this difference may have been caused by the difference in the number of the men and women who were included in the study-sample.

It was noted that no statistically significant difference existed between mean PAID scores of the groups in terms of age. Mean PAID scores of the patients aged between 56 and 65 were higher as compared with patients of other age groups. The study of Miller et al. [23] reported a negative correlation between age of the patients and mean PAID scores. The study of Fonda et al. [18] established that there was no statistically significant difference between the groups in terms of age and mean PAID scores.

No statistically significant difference existed between groups in terms of mean 
PAID scores in relation with educational status. It was seen that patients with higher education degree had fewer problems as compared with others. It was seen in the study of Huis In 'T Veld et al. [22] that mean PAID scores of those with high educational status had lower mean PAID scores and the difference between the groups was statistically significant. It may be concluded that those with higher educational status may have more knowledge about diabetes control, diabetes care and $\mathrm{HbA1c}$.

No statistically significant difference existed between groups in terms of mean PAID scores in relation with professions. Patients who were self-employed had more serious problems as compared with other professional groups. A study of Elkoca [11] revealed that there was a significant difference between profession of the patients and mean PAID scores and those unemployed had more serious problems in diabetes than other professional groups. Because educational level of those who work in self-employed jobs was lower than educational level of other professional groups and there was a higher risk for unemployment in selfemployed jobs, they were more inclined to psychological problems, which may affect their disease perception level.

A statistically insignificant correlation was seen between the groups in terms of mean PAID scores in relation with disease duration. The studies of Welch et al. [19] Snoek et al. [24] demonstrated that no significant correlation existed between disease duration and mean PAID scores. Our study results were in agreement with the results of Welch et al. [19] and Snoek et al. [24]. In a study conducted by Eom et al. [17], it was seen that patients with longer disease duration had higher mean PAID scores and there existed a significant correlation.

In the current study, a statistically significant correlation existed in terms of mean PAID scores in relation with BMI values. According to the results of the study by Turkish Endocrinology Metabolism Association, it was established that glucoses intolerance increased with obesity [25] [26]. There are scientific studies and literature knowledge that emphasize that weight loss in obese individuals plays a key role in coping with problem areas in diabetes, which is similar to our study results [27].

\section{Conclusions and Suggestions}

In light of the results of the study which was conducted in order to determine problem areas of Type II diabetes patients and the affecting factors, the following results were obtained:

- It was determined that general opinion related to problem areas of the participant diabetes patients was "serious problem".

- No significant correlation existed in mean PAID scores of the participant patients in terms of gender, age, education, marital status, profession, family type, disease duration and diabetes history.

- A significant correlation was established between BMI and mean PAID scores. PAID scores of those who were slightly overweight were found to be higher. 
In light of these results, it is recommended that:

- The correlation between individual problem areas in diabetes and the affecting factors should be investigated in relation with different geographic regions.

- Studies to investigate the same subject should be conducted in a longer time period using a bigger sample group.

- Social training activities should be given about obesity and obesity-caused health problems.

\section{Acknowledgements}

This study was thesis for Master degree in Internal Diseases Nursing that approved in Health Sciences Institute and Atatürk University. Authors appreciated the all participants and persons which helped them in each steps of the study. The authors declare that there is no conflict of interest.

\section{References}

[1] International Diabetes Federation (2012) IDF Diabetes Atlas. http://www.idf.org/diabetesatlas/5e/the-global-burden

[2] American Diabetes Association (2009) Standards of Medical Care in Diabetes. Diabetes Care, 32, S13-S61.

[3] World Health Organization (2011) Diabetes Fact Sheet No 312. Department of Chronic Diseases and Health Promotion. http://www.who.int/mediacentre/factsheets/fs312/en/

[4] Onat, A., Hergenç, G., Uyarel, H., Can, G. and Özhan, H. (2006) Prevalence, Incidence, Predictors and Outcome of Type 2 Diabetes in Turkey. Anadolu Kardiyoloji Dergisi, 6, 314-321.

[5] Kara, B. (2006) The Correlation between Anxiety and Metabolic Control in Type II Diabetes Patients. Health and Society, 16, 36-40. https://doi.org/10.2337/dc09-S013

[6] World Health Organization (2011) Diabetes Fact Sheet NO.312. http://www.who.int/mediacentre/factsheets/fs312/en/index.html

[7] Durna, Z. (2002) Classification of Diabetes and Diagnosis Criteria. In: Erdoğan, S., Ed., Basic Knowledge of Diabetes Nursing, Supreme Commercial/Publication/Distribution, Istanbul, 11-13.

[8] Gündoğdu, S. and Açbay, Ö. (2003) Phases of Type II Diabetes and Follow-Up Criteria. Actual Med Diabetes Form, 8, 10-13.

[9] Demir, H. (2010) Coaching Approaches in Diabetes Education. Yeditepe University Medical Faculty Hospital, Diabetes Clinics, 2, 73.

[10] Sherwin, R. (2004) Diabetes Mellitus. In: Ünal, S., Ed., Cecil Textbook of Medicine, W B Saunders Co, Istanbul, 1424-1451.

[11] Elkoca, A. (2010) Evaluation of Attitudes of Type II Diabetes Patients towards the Disease and the Correlation between Problem Areas and Their Attitudes. Master's Thesis, Health Sciences Institute, Department of Internal Diseases Nursing, Atatürk University, Erzurum.

[12] Dinççağ, N. (2001) Training of the Patients with Diabetes Mellitus. In: Yenigün, M. and Altuntaş, Y., Eds., Diabetes Mellitus at all Points, Nobel Medical Book, Istanbul, 997-1002.

[13] Özcan, Ş. (2001) Management of Diabetes Mellitus Patients and Nursing. In: Ye- 
nigün, M., Ed., Diabetes Mellitus at all Points, 2nd Edition, Nobel Medical Book, Istanbul, 969-996.

[14] Polonsky, W.H., Anderson, B.J., Lohrer, P.A., Welch, G., Jacobson, A.M., Aponte, J.E. and Schwartz, C.E. (1995) Assessment of Diabetes-Related Distress. Diabetes Care, 18, 754-760. https://doi.org/10.2337/diacare.18.6.754

[15] Delehanty, L.M., Grant, R.W., Wittenberg, E., Bosch, J.L., Wexler, D.J., Cagliero, E. and Meigs, J.B. (2006) Association of Diabetes-Related Emotional Distress with Diabetes Treatment in Primary Care Patients with Type 2 Diabetes. Diabetic Medicine, 24, 48-54. https://doi.org/10.1111/j.1464-5491.2007.02028.x

[16] Nozaki, T. and Morita, C. (2009) Relation between Psychosocial Variables and the Glycemic Control of Patients with Type 2 Diabetes: A Cross-Sectional and Prospective Study. BioPsychoSocial Medicine, 19, 3-4. https://doi.org/10.1186/1751-0759-3-4

[17] Eom, Y., Park, H., Kim, S., et al. (2011) Evaluation of Stress in Korean Patients with Diabetes Mellitus Using the Problem Areas in Diabetes-Korea Questionnaire. Diabetes \& Metabolism Journal, 35, 182-187. https://doi.org/10.4093/dmj.2011.35.2.182

[18] Fonda, S., McMahon, G., Gomes, H. and Conlin, P. (2009) Changes in Diabetes Distress Related to Participation in an Internet-Based Diabetes Care Management Program and Glycemic Control. Journal of Diabetes Science and Technology, 3, 117-124. https://doi.org/10.1177/193229680900300113

[19] Welch, G., Weinger, K., Anderson, B. and Polonsky, H. (2003) Responsiveness of the Problem Areas in Diabetes (PAID) Questionnaire. Diabetic Medicine, 20, 69-72. https://doi.org/10.1046/j.1464-5491.2003.00832.x

[20] Snoek, F.J. (2002) Breaking the Barriers to Optimal Glycemic Control-What Physicians Need to Know from Patients' Perspectives. International Journal of Clinical Practice, 129, 80-84.

[21] Ghanbari, A., Yekta, Z.P., Roushan, Z.A. and Lakch, N.M. (2005) Assessment of Factors Affecting Quality of Life in Diabetic Patients in Iran. Public Health Nursing, 22, 311-322. https://doi.org/10.1111/j.0737-1209.2005.220406.x

[22] Huis In 'T Veld, E., Makine, C., Nouwen, A., Karşıdağ, Ç., Kadığlu, P., Karşıdağ, K. and Pouwer, F. (2011)Validation of the Turkish Version of the Problem Areas in Diabetes Scale. Cardiovascular Psychiatry and Neurology, 2011, Article ID: 315068.

[23] Miller, S. and Elasy, T. (2008) Psychometric Evaluation of the Problem Areas in Diabetes (PAID) Survey in Southern, Rural African American Women with Type 2 Diabetes. BMC Public Health, 8, 70. https://doi.org/10.1186/1471-2458-8-70

[24] Snoek, F.J., Pouwer, F., Welch, G.W. and Polonsky, W.H. (2000) Diabetes-Related Emotional Distress in Dutch and US Diabetic Patients. Diabetes Care, 23, 13051309. https://doi.org/10.2337/diacare.23.9.1305

[25] Yıldız, E. (2008) Obesity and Type II Diabetes. Turkish Health Ministry, Klasmat Publication, Ankara.

[26] Satman, I. (2000) Study on the Prevalence of Endocrinology Diseases II. Diabetologia, 43, 433.

[27] Satman, I., Yilmaz, T., Sengül, A., Salman, S., Salman, F., Uygur, S., et al. (2002) Population-Based Study of Diabetes and Risk Characteristics in Turkey: Results of the Turkish Diabetes Epidemiology Study (TURDEP). Diabetes Care, 25, 15511556. https://doi.org/10.2337/diacare.25.9.1551 
Submit or recommend next manuscript to SCIRP and we will provide best service for you:

Accepting pre-submission inquiries through Email, Facebook, LinkedIn, Twitter, etc. A wide selection of journals (inclusive of 9 subjects, more than 200 journals)

Providing 24-hour high-quality service

User-friendly online submission system

Fair and swift peer-review system

Efficient typesetting and proofreading procedure

Display of the result of downloads and visits, as well as the number of cited articles Maximum dissemination of your research work

Submit your manuscript at: http://papersubmission.scirp.org/

Or contact jdm@scirp.org 